\title{
The Effectiveness of a Jail Diversion Program in Linking Participants to Federal Entitlements and Stable Housing
}

\author{
Sabrina W. Tyuse \\ St. Louis University
}

\begin{abstract}
Jail diversion programs are designed to prevent the incarceration of mentally ill offenders and to facilitate their entrance into appropriate community-based treatment, while also guarding the safety of the general public. This study sought to determine the effectiveness of one such program. Initial outcomes are described for mentally ill offenders who participated in the program. A total of 50 participants completed the following self-report measures: the Government Performance and Result Act (GPRA) instrument, and the Colorado Symptom Index. Participants were interviewed again at 6 and 12 months. Results indicate the program significantly assisted participants in obtaining income supports such as Medicaid, Social Security, and Food Stamp benefits, but had little impact on housing outcomes.
\end{abstract}

(c) 2005 Californian Journal of Health Promotion. All rights reserved.

Keywords: mental illness, jail diversion, income supports, housing

\section{Section I: Introduction}

Incarceration levels in U.S. prisons have increased significantly since the 1980s. For example, 503,586 people were incarcerated in jails and prisons in 1980 (BJS, 2002). In 2003, this number increased to more than 2 million (Harrison \& Karberg, 2004). Many of these inmates have mental health problems; a 1997 survey estimated 16 percent of jail and state prison inmates and 7 percent of federal inmates - a total of 283,000 prisoners - had a mental illness (Ditton, 1999). Torrey (1995) and Torrey et al., (1992) refer to the jails as “America's new mental hospitals" based on their finding that, on any given day, twice as many people with mental illness are in jails and prisons than are in public psychiatric hospitals. In fact, Los Angeles County Jail, Chicago's Cook County Jail, and New York's Riker's Island Jail alone hold more people with mental illness each day than any psychiatric facility in the United States (Torrey, 1999).

It is widely accepted that the high number of inmates with mental illness is attributable, at least in part, to the deinstitutionalization, beginning in the 1960s, of those requiring psychiatric services (Lamb, 1998; Lamb \&
Weinberger, 1998; Mobray \& Holter, 2002; Ryglewicz, 1996; Sigurdson, 2000; Smiley, 2001; Torrey, 1997). This change in mental health care delivery was largely driven by cost and staff pressures, evolving civil rights, and breakthroughs in the development of psychotropic drugs (Perez, Leifman, \& Estrada, 2003). Sadly, deinstitutionalization also resulted in the discharge of a large number of patients from psychiatric hospitals without a corresponding increase in community-based mental health and support services or systems (Bachrach, 1983; Dvoskin \& Steadman, 1994; Perez, Leifman, \& Estrada, 2003). In Missouri, for example, the psychiatric hospitalization rate decreased by 91 percent between 1955 and 1994, and in California, the decrease was 90 percent (Davoli, 2003).

Over-time, the lack of adequate community mental health services and supportive care led to homelessness and increasing incarceration rates among the mentally ill population (Desai, Lam, \& Rosenheck, 2000; Gilligan, 2001; Perez, et al., 2003; Lamb, 1998; Lamb \& Weinberger, 1998). For example, Gilligan (2001, p. 47) notes that as mental hospitals were "shut down or torn down, the prison population exploded to 
dimensions unprecedented in the history of this country.” Increasingly, many who are mentally ill come into contact with the criminal justice system (Desai, 2003; Lamberti et al., 2001) and once released, they are often homeless and over time are rearrested (Lamb \& Weinberger, 2001; Sigurdson, 2000).

\section{Jail Diversion Program Background Purpose and Definition}

One initiative to decrease the number of mentally ill persons who are incarcerated is the development of jail diversion programs (JDPs). The TAPA Center (2004, p. 1) observed that JDPs are "programs that divert individuals with serious mental illness (and often co-occurring substance use disorders) in contact with the justice system from jail and [that] provide linkages to community-based treatment and support services.” Jail diversion programs are designed to prevent the incarceration of mentally ill offenders (Draine \& Solomon, 1999) and to facilitate their placement into appropriate community-based treatment, while at the same time ensuring public safety. The goals of JDPs are to link clients to mental health treatment and to reduce the number of days spent in jail.

\section{History}

Jail diversion programs grew out of concern regarding the inadequate and inappropriate treatment of mentally ill offenders in the criminal justice system (Osher, Steadman, \& Barr, 2003; Ruddell, Roy, \& Diehl, 2004; Steadman \& Veysey, 1997). Ditton (1999), for example, reported that 59 percent of mentally ill offenders in jails and 40 percent of mentally ill offenders in prison receive no mental health treatment. Studies over the past two decades have found that incarcerated mentally ill offenders were denied or refused access to psychiatric medications (Torrey et al., 1992), thus exacerbating their mental health problems. Moreover, mentally ill individuals were more likely to be victimized by other inmates (Davoli, 2003; French, 1987) and more likely than other inmates to become homeless upon release (French, 1987; O’Flaherty, 1996). Such concern for the welfare of mentally ill offenders led some communities to develop and implement jail diversion programs to link offenders to community-based treatment services. By the mid-1990s, 54 such programs were operational (Steadman, Barbera, \& Dennis, 1994). Today there are 294 diversion programs throughout the country (TAPA, 2003).

\section{Effectiveness of Early Programs}

Jail diversion programs usually take one of two forms: pre-booking and post-booking. In a prebooking JDP, the individual is considered for entry before a formal arrest has been made or before the person is jailed. This form of diversion is usually handled by a police officer or an outreach team composed of police and mental health professionals (Steadman, Strainbrook, Guffin, Draine, Dupont, \& Horey, 2001). The diversion is usually to a mental health treatment facility (Lamb, et al., 1995). The post-booking jail diversion model, on the other hand, considers individuals for program admission only after they are officially detained, arrested, and identified as having committed an offense.

Although several jail diversion program research studies are underway, to date, only seven have been published. Two early pre-booking program studies evaluated whether outreach with mental health-trained professionals and police officer teams could effectively divert mentally ill offenders from jail to mental health treatment facilities. Lamb, Shaner, Elliot, DeCuir, and Foltz (1995) found that most mentally ill offenders were transported to hospitals or mental health treatment facilities. In addition, evaluations of two police-based outreach programs (the Memphis Crisis Intervention Team and the Birmingham Community Service Officers program) found a reduction in the numbers arrested and an increase in offenders being linked to treatment (Steadman, Williams, Borum, \& Morrissey, 2000).

One form of post-booking JDP includes the use of mental health courts. These courts are used at the pre-sentencing stage to divert defendants with mental illness from the criminal justice system or at the post-sentencing phase to prevent incarceration and reduce time on probation (Goldkamp \& Irons-Guyns, 2000). Specifically, mental health courts usually provide; (1) a court 
docket specifically set aside for people with mental illness; (2) a team of criminal justice and mental health professionals to recommend a treatment and supervision plan and identify a responsible party; (3) assurance that the recommended treatment is available to the defendant/client; and (4) court monitoring with possible sanctions for noncompliance, such as reinstituting charges or sentences (Steadman, et al., 2001).

Three court-based, mental health programs showed better outcomes for those diverted into treatment than for those who proceeded along the regular criminal justice track. A study by Cosden, Ellens, Schnell, Yamini-Diouf, and Wolfe (2003) reported that at the one year follow-up interview, offenders who were under the supervision of the mental health court were more likely to be drug-free and living independently than those who were initially jailed and released without mental health court supervision (although, over time, both groups reported similar improvements in quality of life and reductions in psychiatric symptoms). In addition, evaluation of a mental health court program in Los Angeles (Lamb, Weinberger, \& Reston-Parham, 1996) found that offenders with court supervision had better outcomes than those not supervised. One program that also monitored days of incarceration found a reduction in jail time for those diverted to treatment versus those not diverted (Steadman, Cocozza, \& Veysey, 1999).

Evaluations of two of the earliest-implemented jail-based programs found that the combination of diversion and psychiatric treatment resulted in fewer days spent in jail. An evaluation by Hoff, Baranosky, Buchanan, Zonana, and Rosenheck (1999) of the jail diversion program in New Haven, Connecticut, for example, found that those in the experimental group spent fewer days in jail in the year following program enrollment than did those in the control group. This was especially true for those who were initially arrested for more serious minor-level crimes (Class D felonies and Class A misdemeanors). Another evaluation, conducted by Project Link (1999), reported similar outcomes with its 46 program enrollees as days in jail dropped from
9.1 to 2.1 days in the year following program enrollment. Lamberti et al. (2001) also found that Project Link, which included a continuum of services, including social and income supports, was successful in reducing jail time among participants.

The success of the earlier programs, as well as continuing concern for the welfare of mentally ill offenders, led the Substance Abuse and Mental Health Services Administration (SAMHSA), part of the Department of Health and Human Services, to award three-year grants to 20 communities to develop jail diversion programs. St. Louis, Missouri, received one such grant and subsequently developed a jail diversion program. It is this JDP that is evaluated and discussed below.

\section{Section II: Process Evaluation} The St. Louis, Missouri Jail Diversion Program

Process evaluations describe and provide an understanding of the program's characteristics to measure what is done by the program, and to identify those for whom services were provided and received. Specifically, the process evaluation is used to ascertain what features of the program contribute to its success or failure. The purpose of the St. Louis JDP is to divert mentally ill offenders from the criminal justice system to community-based treatment services. Offenders who are admitted into the jail diversion program receive intensive, short-term case management (30-90 days) with the goal of optimizing the use of mental health services and to reduce re-arrest rates over time (Ruddell et al., 2004; Ventura, Cassel, Jacoby, \& Huang, 1998). The St. Louis JDP was developed through negotiation and coordination of efforts by criminal justice staff at local detention facilities and community-based mental health providers.

\section{Promotion}

Education and Health Service Similar to other jail diversion programs, the St. Louis JDP also works to build coalitions between the criminal justice system and mental health treatment providers to support and encourage treatment, employment, education, 
social skills training, and quality of life activities. Although the purpose of the JDP is to divert appropriate mentally ill misdemeanants from jail to community-based treatment programs, an overarching goal is to educate program participants and the community about mental illness thereby promoting healthier behaviors. For example, JDP mental health promotion services are geared toward linking participants to services, federal entitlements programs, skills training, physicians, education, employment, and housing opportunities. Moreover, St. Louis JDP personnel assist in Crisis Intervention Team (CIT) workshop programs designed to educate police officers, corrections personnel, and emergency room professionals about the needs of the mentally ill offender. To further educate the community, the St. Louis JDP disseminates information about the project through newsletter and magazine articles that are distributed to all law enforcement agencies, as well as to local courts. They also present papers at health and social science conferences. The St. Louis JDP's consumer representative and family support specialist has also delivered presentations at public events, as well as provided in-service training to mental health providers. These activities are undertaken to educate, promote healthier behaviors, and improve the quality of life for the mentally ill and for the communities in which they reside.

\section{Eligibility Criteria}

The St. Louis JDP, which began operation in February 2003 and will continue through December 2005, is designed for individuals who are suffering from serious mental illness. To qualify for the program, individuals must have a known diagnosis on Axis 1 (Schizophrenia Spectrum, Bipolar Disorder, Depressive Disorder, Substance Abuse Disorder, etc.) or report a significant history of repeated hospitalizations and/or medications for mental illness. In addition, these individuals must meet both criminal and mental illness criteria, they must be adults (18 years or older), residents of the St. Louis metropolitan area, and arrested in the area for nonviolent, misdemeanor offenses. Eligibility criteria also include, but are not limited to the following; (1) the nature of the current offense(s), (2) history of incarceration, (3) current mental status, (4) availability of mental health resources, and (5) public safety factors. Exclusions from eligibility include felony-level charges, exclusive alcohol or drug use with no signs of mental illness, current charges of driving while intoxicated or driving under the influence, and violent crimes. Eight persons in this sample, were, however, accepted as their felony charges were non-violent. Typical charges of JDP clients include trespassing, disorderly conduct, public intoxication, public urination, indecent exposure, insufficient funds check writing, shoplifting, loitering, and petty larceny.

Mental illness criteria include co-occurring disorders (substance abuse and mental illness), behaviors associated with mental illness, selfdisclosure of symptoms/treatment of mental illness, and self-disclosed or observed experiencing of acute psychiatric crisis. The 2003 National Survey on Drug Use and Health (NSDUH) found that a diagnosis of Seriously Mentally Ill (SMI) and substance abuse are highly correlated. Specifically, the NSDUH (2003, p. 76) reported that 21.3 percent of adults with SMI "were dependent on or abused alcohol or illicit drugs, while the rate among adults without SMI was only 7.9 percent.” Therefore, the JDP developed services to address the unique needs of those with substance abuse issues.

\section{Participants}

Program participants are expected to engage in mental health treatment for no less than 30 days and (usually) no more than 90 days (although time in the program may be extended in some cases). During this time, participants are helped to develop and implement goals and objectives that will lead to successful social, financial, and personal outcomes. Clients exit the program in one of three ways; (1) successful graduation from the program (the client successfully completes the 30 to 90-day treatment plan); (2) termination for violation of program rules, such as failing to participate in required activities (for example, not attending counseling sessions); and (3) voluntary exit from the program prior to completion. 


\section{Admissions Procedures}

Although most participants enter the JDP via the criminal justice system, referrals to the program also can be made by jail personnel, judges, prosecutors or public defenders, family members, self-referrals, probation office staff, mental health service providers, CIT police officers, or nurses at the correctional facilities. CIT police are officers who have voluntarily completed 40 hours of training in psychiatric disorders, drug abuse education, community mental health resources, and behavioral deescalation techniques for handling and diverting mentally ill persons into appropriate treatment services (Vickers, 2000). The emphasis of CIT training is for officers to divert mentally ill offenders, when appropriate, from the criminal justice system to community-based mental health treatment services.

Most referrals, however, are made by medical nurses at the correctional facility. This is largely because offenders detained in the local criminal justice system receive a medical screening within hours of arriving at the detention facility. This screening evaluates health conditions, including the presence of mental illness or substance abuse. Nurses refer appropriate candidates to the JDP. Upon release from custody, a case manager transports the potential JDP client to the mental health treatment facility for a more comprehensive mental health evaluation. Those who meet the eligibility criteria and volunteer to participate are accepted into the program.

\section{Intensive Case Management}

Previous research by Osher et al. (2003) and by Randolf, et al. (1997) note the need for "wraparound" services for the mentally ill, which should include; treatment, health care, benefits search or entitlements access, housing assistance, and help with the legal system. To address these unique needs, JDP services at the treatment provider site are designed to be a "one-stop shop" - that is, the mental health facility is designed to meet most, if not all, client support service needs in one location. At the facility, clients can access housing resources (information about homeless shelters, transitional housing, and permanent housing options), a Department of Family Services (DFS) caseworker, entitlement applications, psychiatric services, and personal services such as shower and laundry facilities.

St. Louis JDP services are modeled on a program considered an exemplary practice for interventions with the mentally ill population: the Program of Assertive Community Treatment (PACT) (Stein \& Test, 1980). The PACT model includes a psychiatrist/psychiatric nurse for medication management and oversight, comprehensive case management services, assertive outreach, intensive support levels, and a low staff-to-client ratio (ten to 12 clients are typically assigned to each case manager) (Drake \& Burns, 1995). PACT has been shown to improve clinical results with mentally ill, nonhomeless populations (Bond, Miller, Krumwied, \& Ward, 1988; Grahl, 1998; McFarlane, Stastny, \& Deakins, 1992; Merson, Tyrer, \& Onyett, 1992; Rosenheck, Frisman, \& Neale, 1994), as well as to provide independence in living situations (Test, 1992) and increased service satisfaction (Merson et al., 1992; Rosenheck et al., 1994; Test, 1992). The mental health treatment portion of the JDP, although not fully implementing PACT team services, draws from the most effective methods of the model, while incorporating additional research-based findings for short-term interventions.

Each client is assigned an intensive case manager (ICM) who links the client to appropriate services, resources, and entitlements, as well as legal benefits through the jail diversion program. ICMs are staff members of the mental health facility and all are masterslevel social workers. Each ICM works with ten to 12 clients to develop goals and objectives for their 30 to 90-day treatment program, and meets with each client two to five times a week. The ICM facilitates appointments with in-house psychiatric staff and assists with referrals to a medical doctor or other medical services. ICMs manage clients' physician appointments and access to medications, which are prescribed and made available through an on-site pharmacy system. They schedule other types of appointments (such as court dates and searches 
for housing and employment) and arrange for transportation to those appointments. Intensive case management continues until a client is stabilized for transfer to a longer-term treatment case manager, referred to other appropriate services (for example, medical management only), or discharged. As a result, the JDP is designed to give participants access to a continuum of services that assist them in becoming healthy, fully functioning members of society.

Clients who are unemployed or who may be eligible for, but are not receiving, federal entitlements are required to meet with a benefits specialist and a Department of Family Services worker to discuss eligibility for government entitlement programs, such as Social Security, Medicaid insurance, Food Stamps, and veterans benefits. If necessary, clients are also required to meet with an employment and housing specialist. The intensive case manager also assists clients in getting copies of their social security card and birth certificate. These forms of identification are necessary for many housing and entitlement applications, and most program clients (95 percent) had lost their Social Security card and had no other form of official identification. Moreover, the mental health treatment facility has more than 100 contract providers to meet clients' cultural- and genderspecific needs, as well as linking them to a full array of psychiatric specializations.

\section{Housing}

Research has consistently demonstrated that the homeless who are mentally ill require help to secure stable housing arrangements and access to benefits is fundamental to reducing homelessness among the mental ill (Sullivan, Burnam, Koegel, \& Hollenberg, 2000). In fact, Sullivan et al. (2000) reported that one in five mentally ill people have difficulty locating and securing stable housing. Moreover, according to the Federal Task Force on Homelessness and Severe Mental Illness (1992), those who are homeless are less likely to seek treatment, tend to be severely impaired, and have greater service needs than those with housing. Stable housing is important for this population as Culhane, Metraux, \& Hadley (2002) found that the homeless mentally ill (HMI) who do secure supportive housing are less likely to be homeless in the year preceding access, use emergency shelters, or be rearrested and incarcerated (see also Rapp, 1998; Shern et al., 1997). Culhane et al. (2002) also quantified the importance of supportive housing for this population, reporting a 38 percent reduction in jail days and an 84 percent reduction in prison days for HMI who secured supportive housing.

Recognizing that homelessness is a concern for this population and to promote the continuity of supervision and ensure the successful treatment of individuals who are diverted and homeless, the St. Louis JDP provides services designed to address the unique needs (Goldkamp \& IronsGuynn, 2000) of the homeless mentally ill. These services include an intensive case manager who refers and links participants to federal entitlement programs and, if necessary, to a housing counselor who assists the participant in finding an appropriate residence. The housing counselor assists in locating stable long-term or permanent housing, such as group homes, private apartments, supported community living, or Housing Authority and Section Eight Voucher Program units. St. Louis provides a rental assistance program for the HMI, called the Shelter Plus Care Voucher Program (SCVP). This program is designed to help provide long-term or permanent supportive rental housing for hard-to-serve homeless persons with disabilities including mental illness (U.S. Department of Housing and Urban Development, 2004).

The housing counselor maintains contact with clients and landlords. Such continued contact helps to create a successful transition as many formerly homeless mentally ill persons who have been living on the streets initially feel isolated or disoriented residing in a private apartment (Susser et al., 1997). Understanding this reality, the housing counselor conducts follow-up conversations with clients and landlords to ascertain how the transition is progressing and continues these follow-up calls with landlords every six months, as long as the client is using the Shelter Plus Care Voucher Program. 
St. Louis JDP clients also have access, as needed, to an Emergency Homeless Fund in times of crisis. These funds can be used for apartment down payments, utility deposits, and emergencies such as payments to stave off eviction. In addition, they can be used to purchase copies of birth certificates or state identification.

\section{Section III: Description of the Evaluation Study}

\section{Method and Sample}

The purposes of the evaluation of the St. Louis jail diversion program were; (a) to gather information about the development and operation of the JDP; and (b) to evaluate the effectiveness of the JDP in linking clients to federal entitlements and income supports and, when necessary, to permanent housing arrangements. The population of interest for this study are the 50 JDP participants enrolled in the research portion of the program in St. Louis between September 16, 2003, and December 16, 2004, who met the criteria listed above (e.g., misdemeanor offenders arrested for non-violent offenses).

On average, study participants (Table 1) were 33 years of age. Fifty percent were high school graduates or had earned a GED and the average education level was 11 years. The majority of participants were male (56 percent) and AfricanAmerican (60 percent), and the remaining participants were White. In terms of illness history, the primary diagnoses were depressive disorders (38 percent), bipolar disorders (32 percent), and schizophrenia (20 percent). When comparing the sample by race (Figure 1), we found that African Americans were more likely to be diagnosed with depressive disorder (43 percent) and schizophrenia (23 percent) than were Whites (30 percent and 15 percent respectively). Whites, however, were more likely to be diagnosed bipolar (45 percent). These results are consistent with previous studies of race, mental illness, and diagnoses, which find that African Americans are more likely than Whites to be diagnosed with schizophrenia (Chow, Jaffee, \& Snowden, 2003; Trierweiler et al., 2000).

A total of 44 percent of participants reported stable housing arrangements at baseline (see Table 1), whereas roughly 23 percent reported being homeless and an additional 33 percent reported that they were "doubled-up" (staying with a relative or friend in an unstable living arrangement). Both groups were counted as homeless in the analysis. Sample data also indicated 78 percent of participants, in addition to being mentally ill, had a dual diagnosis, meaning they also suffered from substance abuse or addiction. Those with a dual diagnosis tended to be male (62 percent), AfricanAmerican (54 percent), about 34 years of age, high school dropouts (54 percent), homeless (54 percent), and without Social Security benefits (67 percent) when they entered the program (data not shown).

Of those with a dual diagnosis, 44 percent reported an addiction to crack cocaine, 23 percent reported that they abused alcohol, and another 23 percent reported they used marijuana on a regular basis. Similar results have been reported in previous studies. For example, Weiss (1992) and Hartwell (2004) found that about 80 percent of mentally ill offenders either were current substance abusers or had abused substances at some point in their lifetimes. Hartwell (2004) also found that 62 percent of mentally ill offenders in her study were drug abusers. Moreover, the study revealed that these individuals were also more likely to be homeless and to have contact with the criminal justice system. 
Table 1

Demographic and Socioeconomic Characteristics of Jail Diversion Program Participants (N=50)

\begin{tabular}{|c|c|c|}
\hline Characteristics & Percent & $\mathbf{N}$ \\
\hline \multicolumn{3}{|l|}{ Gender } \\
\hline Male & 56.0 & 28 \\
\hline Female & 44.0 & 22 \\
\hline \multicolumn{3}{|l|}{ Race/Ethnicity } \\
\hline African American & 60.0 & 30 \\
\hline Caucasian & 40.0 & 20 \\
\hline Age (mean) & 33.0 & 50 \\
\hline \multicolumn{3}{|l|}{ Education } \\
\hline High school graduate (or GED) & 50.0 & 25 \\
\hline Average years of education & 10.6 & \\
\hline \multicolumn{3}{|l|}{ Employment } \\
\hline Employed (full- or part-time) & 22.0 & 11 \\
\hline Earnings (median) per month & $\$ 90.00$ & \\
\hline \multicolumn{3}{|l|}{ Location } \\
\hline St. Louis County & 66.0 & 33 \\
\hline St. Louis City & 34.0 & 17 \\
\hline \multicolumn{3}{|l|}{ Housing Status } \\
\hline Homeless at baseline & 56.0 & 27 \\
\hline Homeless at follow-up & 46.0 & 22 \\
\hline \multicolumn{3}{|l|}{ Primary Diagnosis } \\
\hline Depressive Disorder & 38.0 & 19 \\
\hline Bipolar Disorder & 32.0 & 16 \\
\hline Schizophrenia Spectrum & 20.0 & 10 \\
\hline Other (PTSD, etc.) & 10.0 & 5 \\
\hline Dual Diagnoses & 78.0 & 39 \\
\hline Crack cocaine & 44.0 & 17 \\
\hline Marijuana & 23.0 & 9 \\
\hline Alcohol & 23.0 & 9 \\
\hline Heroine & 3 & 3 \\
\hline Other (prescription drugs, etc.) & 2.6 & 1 \\
\hline \multicolumn{3}{|l|}{ Entitlements at Baseline } \\
\hline Social Security (SSI, SSDI) at baseline & 26.0 & 13 \\
\hline Social Security (SSI, SSDI) at follow-up & 53.0 & 25 \\
\hline Medicaid at baseline & 8.0 & 4 \\
\hline Medicaid at follow-up & 62.0 & 31 \\
\hline Food Stamps at baseline & 34.0 & 17 \\
\hline Food Stamps at follow-up & 40.0 & 20 \\
\hline \multicolumn{3}{|l|}{ Exit Type } \\
\hline Successful graduation (or expected) & 66.0 & 33 \\
\hline Voluntary exit (before completion) & 16.0 & 8 \\
\hline Incarcerated & 10.0 & 5 \\
\hline Terminated & 8.0 & 4 \\
\hline
\end{tabular}




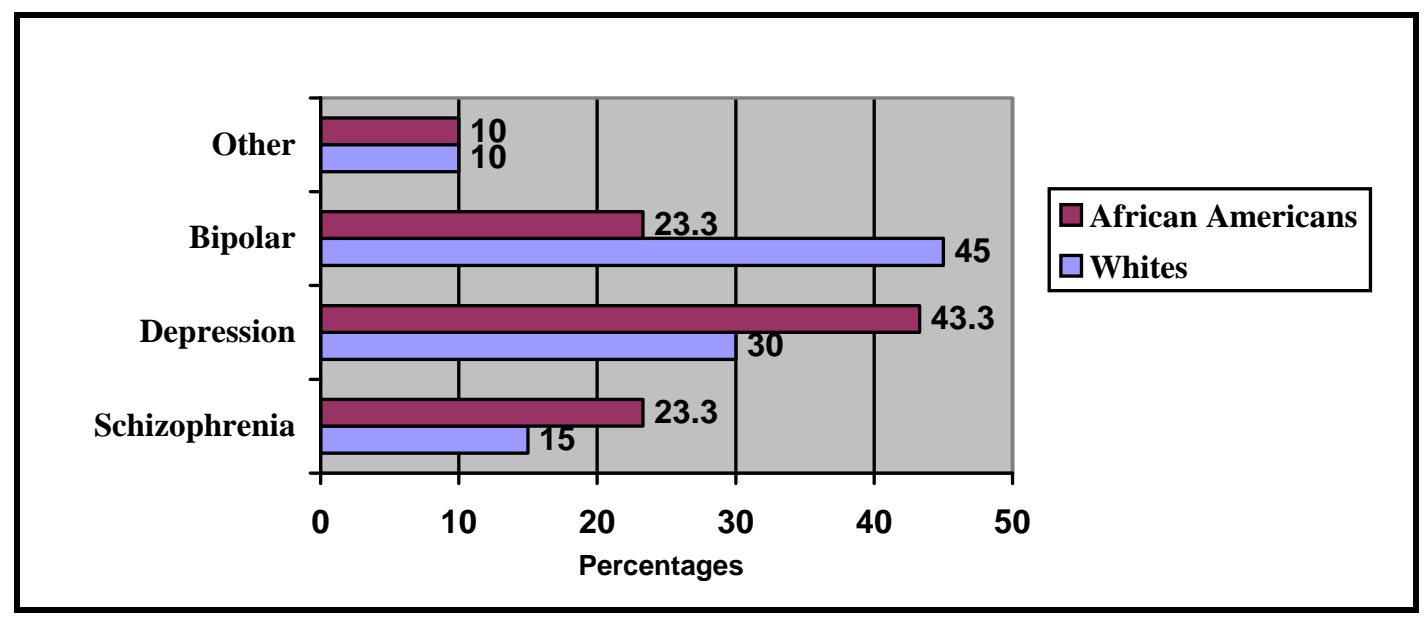

Figure 1

Psychiatric Diagnoses By Race

\section{Measures}

At baseline, program participants were asked to complete two survey instruments - the Government Performance and Result Act (GPRA) and the Colorado Symptom Index and agree to be re-interviewed at 6 and 12 months from that day. The GPRA instrument collects demographic information (age, sex, race, and education level), their place(s) of residence in the last 30 days and services received since program enrollment. Information from the Colorado Symptom Index was used to assess participants' mental health status. In general, survey instruments were designed to track and measure program effectiveness in linking diverted mentally ill offenders to treatment services, income supports, and housing. Additional participant-level data were collected from the mental health treatment provider and jail records.

\section{Design}

The research method used for the evaluation of the impact of the St. Louis jail diversion program was a pre-post design with reflexive controls. Rossi, Lipsey, and Freeman (2004, p. 290) observe that such a design is "one in which outcomes are measured on the same targets before program participation and again after sufficiently long participation for effects to be expected.” The two sets of measurements are then compared to produce an estimate of the program's effect. Internal validity is an issue, however, as we are trying to evaluate the relationship between treatment effects and participant outcomes. Without a control group for comparative purposes, we cannot conclude the program alone accounted for participant outcomes. Alternative explanations for outcomes exist, (i.e., they may be related to a participant's educational level, maturation, help and support provided by family members, or even to prior participation in other mental health programs). Since available data do not allow a means for measuring alternative explanations, the differences in the two measurements (preand post-) must be interpreted only as a net effect of the intervention (Rossi et al., 2004).

The McNemar test was used to analyze the dichotomous variables - Social Security, Food Stamps, Medicaid, Food Stamps and need for housing - used the McNemar tests. This test is used primarily in pre-post studies to determine whether the amount of change in a research sample is statistically significant or likely due to chance (Weinbach \& Grinnell, 2001). The differences were considered significant at a probability level of $p \leq .05$. 
The evaluation had two dependent, or outcome, measures: Access to federal entitlements (Social Security Disability Insurance [SSDI], Supplemental Security Income [SSI], and Food Stamps). The second outcome variable of interest in this study was access to housing. As mentioned previously, 56 percent of clients reported a need for stable housing. Homelessness was measured in two ways. First, program participants were defined as homeless if, at baseline, they self-reported that they were living in a homeless shelter, living on the streets, or living in an abandoned building. Of the participants, 23 percent reported this type of homelessness. The second definition for homelessness was based on all self-reports, at baseline, of sharing or "doubling-up" with relatives or friends in a living situation that was unstable or could end at any moment. More than 33 percent of the sample reported this type of homelessness. Homelessness was a dichotomous variable denoted by a response of either (1) yes, homeless or (0) no, not homeless.

\section{Section IV: Results}

Of those who entered the program without access to federal entitlements most clients were assisted by ICMs in the application and documentation process required to receive benefits. For example, only 26 percent of participants (Table 2) entered the JDP with social security and disability benefits. By either the six or 12-month follow-up however, the number of participants with social security and/or disability benefits had risen to about 53 percent. This change was significant at the $p \leq$ .001 level (McNemar test, $p \leq .000$ ). Similarly, access to Medicaid rose from eight percent of participants having benefits at baseline to 62 percent having them at follow-up. This change was also significant at the $p \leq .001$ level.

Table 2

Receipt of Federal Entitlements and Housing at Baseline and Follow-Up

\begin{tabular}{|l|c|c|c|}
\hline & Baseline & Follow-Up & Gain \\
\hline Social Security & 25.6 & $53.5^{*}$ & 27.9 \\
\hline Medicaid & 8.0 & 62.0 & 54.4 \\
\hline Food Stamps & 34.0 & 40.0 & 9.5 \\
\hline Homeless & 56.0 & 44.0 & -8.0 \\
\hline Re-incarcerated & 8.0 & & \\
\hline Drug Rehab & 2.0 & & \\
\hline
\end{tabular}

Only 34 percent of participants entered the program with Food Stamp benefits. Of those who remained eligible, about 40 percent were receiving this benefit at the follow-up period. Although more clients were receiving the Food Stamp benefit at follow-up, change in the Food Stamps variable was not statistically significant.

JDP participants who were homeless at baseline tended to be male (55 percent), African American (68 percent), high school graduates (54 percent), and residents of St. Louis County
(73 percent) (data not shown). Of the participants who reported homelessness or a need for housing due to unstable or unsuitable living arrangements (54 percent), very few were able to secure stable housing arrangements. In fact, 44 percent reported being homeless at follow-up. Various reasons were given. Some clients chose to continue living with family members and friends. An additional eight percent had returned to jail, and two percent were in drug rehabilitation programs at followup. 


\section{Section V: Discussion} Outcomes

The St. Louis, Missouri JDP successfully assisted participants in the entitlement application process, helping them to obtain income supports such as Social Security, Medicaid, and Food Stamp benefits. At baseline, 95 percent of program participants were eligible for these programs, but very few were receiving these federal benefits. This speaks to both the need for such programs and to the importance of the program's assistance in helping to link the mentally ill to social services and income supports.

However, the JDP had little impact on housing outcomes. Although these findings are consistent with previous research and add to the mental health literature with regard to the underutilization of federal entitlement programs among the eligible mentally ill, the program's goal of linking participants to stable and secure housing remained unfulfilled for 44 percent of those in need. Although the St. Louis JDP makes funds available to homeless participants, the overriding problem is an insufficient supply of affordable housing available to low-income families. The shortage of affordable housing is particularly problematic for this population as homelessness increases their likelihood of coming into contact with the criminal justice system. Affordable housing, however, is not an issue that can be solved by any one program. Only the resources available to the federal government can address this problem. That being said, however, mental health advocates can work with housing advocates to lobby the federal government to increase the number and availability of affordable housing units. Providing an increased supply of affordable housing to the poor can be expected, at least indirectly, to make additional housing opportunities available for the mentally ill.

\section{Changes to the Program}

Unfortunately, the Jail Diversion Program (JDP) has not enrolled the number of participants that were initially anticipated. JDP personnel identified the initial screening process within the criminal justice system as the major barrier to participation. Initially, the JDP specialist screened all referrals from the jail nursing staff.
This approach, however, did not result in the anticipated number of eligible candidates, and after some additional training, referrals were accepted from virtually all jail staff.

As a result of this change, referrals to the program grew, but the number of individuals found eligible for the JDP did not increase significantly. Ultimately, it was determined that most of the target population was already being referred to a mental health court docket. Since its inception, the St. Louis Mental Health Court has received widespread publicity and community recognition. Consequently, judges, prosecutors and lawyers were aware of the Court and placed mentally ill offenders directly in that program. Over the past year, however, the Jail Diversion Program has become better known throughout the mental health and criminal justice communities. As a result, prosecutors and judges have begun to divert mentally ill offenders who may benefit from the JDP's intensive case management: increasing the number of referrals.

\section{Limitations}

The process evaluation for the St. Louis Jail Diversion Program was limited in several ways. First, it was restricted to residents in two neighboring Midwestern communities, St. Louis City, and St. Louis Missouri. Therefore, care should be exercised in extrapolating results of this study to other geographic areas, such as rural areas, small towns, or other regions of the country. Second, the study was limited by a relatively small sample that included only African Americans and Whites. Hence, the results may not be descriptive of other racial and ethnic groups. Finally, as stated previously, the pre/post design creates internal validity concerns; results may not be due solely to the program influences, but to other unrelated factors.

\section{Conclusions}

Given that JDPs are relatively new endeavors to divert and treat mentally ill misdemeanants from the criminal justice system, further research is needed to describe and understand these programs' processes and effectiveness (McNeece, Springer, \& Arnold, 2001; 
Steadman, Deane, Morrissey, Westcott, Salasin, \& Shapiro, 1999). Particular attention should be paid to comparing outcomes across race/ethnicity, age, gender, and other socioeconomic variables. Further study is also needed on the long-term consequences of program participation to diverted offenders, especially on their outcomes several years after exiting the program.

Clearly, jail diversion programs cannot completely solve the problems of people with mental illness and/or substance abuse when they come into contact with the criminal justice system. Such programs, however, have the potential to benefit members of these highly vulnerable populations. Mental health advocates, therefore, should participate actively in the development and implementation of such programs. With their long history of working with and advocating on behalf of disadvantaged populations, social welfare workers are invaluable in this effort. At the local level, they can work for the creation of drug or mental health courts, JDPs, and other programs that divert persons with mental illness and substance abuse disorders from the criminal justice system. At the state and federal levels, they can actively influence the social policies that guide these systems.

\section{References}

Bachrach, L. L. (1983). Deinstitutionalization. San Francisco: Jossey-Bass.

Bond, G. R., Miller, L. D., Krumwied, R. D., \& Ward, R. S. (1988). Assertive case management inthree CMHs: A controlled study. Hospital and Community Psychiatry, 39, 411-418.

Chow, J. C., Jaffee, K., \& Snowden, L. (2003). Racial/ethnic disparities in the use of mental health services in poverty areas. American Journal of Public Health, 93, 792-797.

Cosden, M., Ellens, J. K., Schnell, J. L., Yamini-Diouf, Y., \& Wolfe, M. M. (2003). Evaluation of a mental health treatment court with assertive community treatment.Behavioral Science Law, 21, 415-427.

Culhane, D. P., Metraux, S., \& Hadley, T. (2002). The impact of supportive housing for homeless people with severe mental illness on the utilization of the public health, corrections, and emergency shelter systems: The New York Initiative. Housing Policy Debate, 13, 107-163.

Davoli, J. H. (2003). No room at the inn: How the federal Medicaid program created inequities in psychiatric hospital access for the indigent mentally ill. American Journal of Law \& Medicine, 29, 159-183.

Desai, R. A. (2003). Jail diversion services for people with mental illness: What do we really know? In W. H. Fisher (Ed.), Community-based interventions for criminal offenders with severe mental illness(pp. 99-121). Boston: JAI.

Ditton, P. M. (1999, July). Mental health and treatment of inmates and probationers (NCJ174463). Washington, DC: U.S. Department of Justice, Office of Justice Programs, Bureau of Justice Statistics.

Drake, R. E., \& Burns, B. J. (1995). Special section on assertive community treatment: An introduction. Psychiatric Services, 46, 667-668.

Draine, J., \& Solomon, P. (1999). Describing and evaluating jail diversion services for persons with serious mental illness. Psychiatric Services, 50, 56-61.

Dvoskin, J. A., \& Steadman, H. J. (1994). Using intensive case management to reduce violence by mentally ill persons in the community. Hospital and Community Psychiatry, 45, 679-684.

Federal Task Force on Homelessness and Severe Mental Illness. (1992). Outcasts on Main Street: Report of the federal task force on homelessness and severe mental illness. (1992). Washington, DC: Interagency Council on the Homeless.

French, L. (1987). Victimization of the mentally ill: An unintended consequence of deinstitutionalization. Social Work, 32, 502-505.

Gilligan, J. (2001). The last mental hospital. Psychiatric Quarterly, 72, 45-61.

Goldkamp, J. S., \& Irons-Guynn, C. (2000). Emerging judicial strategies for the mentally ill in the criminal caseload: Mental health courts in Fort Lauderdale, Seattle, San Bernardino, and 
Anchorage. (Monograph \# NJC 182504). U.S. Department of Justice, Office of Justice Programs, Bureau of Justice Assistance.

Grahl, C. (November/December, 1998). PACT: Is it the answer? Interview with Mary Ann Test, Ph.D., program for assertive community treatment. Behavioral Health Management, 26-28.

Hartwell, S. (2004). Triple stigma: persons with mental illness and substance abuse problems in the criminal justice system. Criminal Justice Policy Review, 15, 84-89.

Hoff, R. A., Baranosky, M. V., Buchanan, J., Howard Zonana, B. A., \& Rosenheck, R. A. (1999). The effects of a jail diversion program on incarceration: a retrospective cohort study. Journal of American Academy Psychiatry Law, 27, 377-386.

Lamb, H. R. (1998). Deinstitutionalization at the beginning of the new millennium. Harvard Review of Psychiatry, 6, 1-10.

Lamb, H.R., Shaner, R., Elliott, D. M., DeCuir, W. J., \& Foltz, J. T. (1995). Outcome for psychiatric emergency patients seen by an outreach police-mental health team. Psychiatric Services, 46, 1267-1271.

Lamb H. R., \& Weinberger, L. E. (1998). Persons with severe mental illness in jails and prisons: a review. Psychiatric Services, 49, 483-92.

Lamb, H. R., Weinberger, L. E., \& Reston-Parham, C. (1996). Court intervention to address the mental health needs of mentally ill offenders. Psychiatric Services, 47, 275-281.

Lamberti, J. S., Weisman, R. L., Schwarzkopf, S. B., Price, N., Ashton, R. M., \& Trompeter, J. (2001). The mentally ill in jails and prisons: towards an integrated model of prevention. Psychiatric Services, 72, 63-77.

McFarlane, W. R., Stastny, P., \& Deakins, S. (1992). Family-aided assertive community treatment: A comprehensive rehabilitation and intensive case management approach for persons with schizophrenic disorders. New Directions for Mental Health Services, 53, 43-54.

Merson, S., Tyrer, P., \& Onyett, S. (1992). Early intervention in psychiatric emergencies: A controlled clinical trial. Lancet, 339, 1311-1314.

McNeece, C. A., Springer, D. W., \& Arnold, E. M. (2001). Treating substance abuse disorders. In J. B. Ashford, B. D. Sales, \& W. H. Reid (Eds.), Treating adult and juvenile offenders with special needs (pp. 131-169). Washington, DC: American Psychological Association.

Mobray, C. T., \& Holter, M. C. (2002). Mental health and mental illness: Out of the closet? Social Service Review, 76, 135-181.

National Survey on Drug Use and Health. (2003).Prevalence and treatment of mental health problems. Retrieved March 20, 2005, from http://www.oas.samhsa.gov/NHSDA/2k3NSDUH/2k3results.htm\#MH

O’Flaherty, B. (1996). Making room: The economics of homelessness. Boston: Harvard University Press.

Osher, F., Steadman, H.J., \& Barr, H. (2003). A best practice approach to community reentry from jails for inmates with co-occurring disorders: An APIC Model. Crime \& Delinquency, 49, 79-96.

Perez, A., Leifman, S., \& Estrada, A. (2003). Reversing the criminalization of mental illness. Crime and Delinquency, 49, 62-78.

Project Link, Department of Psychiatry. (1999). Prevention of jail and hospital recidivism among persons with severe mental illness. University of Rochester, Rochester, New York. Psychiatric Services, 50, 1477-1480.

Randolf, F., Blasinsky, M., Leginski, W., Parker, L. B., \& Goldman, H. H. (1997). Creating integrated services systems for homeless persons with mental illness: The ACCESS Program. Psychiatric Services, 48, 369-373.

Rapp, C. A. (1998). The strengths model: Case management with people suffering from severe and persistent mental illness. New York: Oxford University Press.

Rosenheck, R., Frisman, L. K., \& Neale, M. (1994). Estimating the capital component of mental health care costs in the public sector. Administration, Policy and Mental Health, 21, 493-509.

Rossi, P. H., Lipsey, M., and Freeman, H. (2004). Evaluation: A systematic approach. Thousand Oaks, CA: Sage Publications, Inc. 
Ruddell, R., Roy, B., \& Diehl, S. (2004). Diverting persons with mental illness from jail: a tale of two states. Corrections Compendium 29, 1-5, 38-42.

Ryglewicz, Hilary. (1996). Lives at risk: Understanding and treating young people with dual disorders (p. 175). New York: Free Press.

Shern, D.L., Tsemberis, S., Winarski, J., Cope, N., Cohen, M., \& Anthony, W. (1997). The effectiveness of psychiatric rehabilitation for people who are street dwelling with serious disability related to mental illness. In W.R. Breakey \& J.W. Thompson (Eds.), Mentally ill and homeless (pp. 119147). Amsterdam: Harwood Academic.

Sigurdson, C. (2000). The mad, the bad and the abandoned: The mentally ill in prisons and jails. Corrections Today, 62, 70-78.

Smiley, A. (2001). Forensic mental health in the United States: An overview. In G. Landsberg, \& A. Smiley (Eds.), Forensic mental health: Working with offenders with mental illness (pp. 1-16). Kingston, NJ: Civil Research Institute.

Steadman, H. J., Barbera, S., \& Dennis, D. L. (1994). A national survey of jail diversion programs for mentally ill detainees. Hospital and Community Psychiatry, 45, 1109-1113.

Steadman, H. J., Cocozza, J. J., \& Veysey, B. M. (1999). Comparing outcomes for diverted and nondiverted jail detainees with mental illnesses. Law and Human Behavior, 23, 615-627.

Steadman, H. J., Davidson, S., \& Brown, C. (2001). Mental health courts: Their promise and unanswered questions. Psychiatric Services, 52, 457-458.

Steadman, H. J., Stainbrook, K. A., Griffin, P., Draine, J., Dupont, R., \& Horey, C. (2001). The need for a specialized crisis response location for effective police-based diversion programs. Psychiatric Services, 52, 219-222.

Steadman, H. J., Williams, D. M., Borum, R., \& Morrissey, J. P. (2000). Comparing outcomes of major models for police responses to mental health emergencies. American Journal of Public Health, 51, 645-649.

Steadman, H. J., Morris, S. M., \& Dennis, D. L. (1995). The diversion of mentally ill persons from jails to community-based services: A profile of programs. American Journal of Public Health, 85, 16301635.

Steadman, H. J., \& Veysey, B. (1997). Providing services for jail inmates with mental disorders. Research in Brief. Washington, DC: National Institute of Justice.

Stein, L. L., \& Test, M. A. (1980). Alternative to mental hospital: I. Conceptual model treatment program, and clinical evaluation. Archives of General Psychiatry, 37, 392-397.

Sullivan, G., Burnam, A., Koegel, P., \& Hollenberg, J. (2000). Quality of life of homeless persons with mental illness: results from the course-of-homelessness study. Psychiatric Services, 51, 11351141.

Susser, E., Valencia, E., Conover, S., Felix, A., Tsai, W., \& Wyatt, R. J. (1997). Preventing recurrent homelessness among mentally ill men: A “critical time” intervention after discharge from a shelter. American Journal of Public Health, 87, 256-262.

TAPA. (2003). What can we say about the effectiveness of jail diversion programs for persons with cooccurring disorders? New York: TAPA Center for jail diversion.

TAPA Center. (2004). What is jail diversion? Retrieved November 15, 2004, from http://www.gainsctr.com/b/tapa/jail/default.asp

Test, M. A. (1992). Training in community living. In R. P. Liberman (Ed.), Handbook of psychiatric rehabilitation (pp. 153-170). New York: MacMillan.

Torrey, E. F. (1999, Autumn). Reinventing mental health care. City Journal, 9(4).

Torrey, E. F. (1997). Out of the shadows: Confronting America's mental illness crisis. New York: John Wiley.

Torrey, E. F. (1995). Jails and prisons: America’s new mental hospitals. American Journal of Public Health, 85, 1611-1613.

Torrey, E. F., Stieber, J., Ezekiel, J., Wolfe, S. M., Sharfstein, J., Nobel, J. H., \& Flynn, L. M. (1992). Criminalizing the seriously mentally ill: the abuse of jails as mental hospitals. Arlington, VA: 
Report to the National Alliance for the Mentally Ill: Washington, DC: Public Citizen’s Health Research Group.

Trierweiler, S. J., Neighbors, H. W., Mundy, C., Thompson, S. E., Binion, V. J., \& Gomez, J. P. (2000). Clinical attributions associated with diagnosis of schizophrenia in African American and nonAfrican American patients. Journal of Consulting and Clinical Psychology, 68, 171-175.

U.S. Department of Housing and Urban Development. (2004). Shelter plus care program (S+C).

Retrieved January 25, 2005, from http://www.hud.gov/offices/cpd/homeless/programs/splusc/index.cfm

Ventura, L. A., Cassel, C. A., Jacoby, J. E., \& Huang, B. (1998). Case management and recidivism of mentally ill persons released from jail. Psychiatric Services, 49, 1330-1337.

Vickers, B. (2000). Memphis, Tennessee, police department's crisis intervention team. Washington, DC: U.S. Department of Justice, Office of Programs, Bureau of Justice Assistance.

Weinbach, R.W., \& Grinnell, R. M. (2001). Statistics for social workers. Boston: Allyn and Bacon.

Weiss, R. (1992). The role of psychopathology in the transition from drug use to abuse and dependence. In M. Glantz, \& R. Pickens (Eds.) Vulnerability to drug abuse (pp. 124-149). Washington, DC: American Psychological Association.

Author Information

Sabrina W. Tyuse, Ph.D.

St. Louis University

E-Mail: tyuses@slu.edu 